\title{
State of the art of the development and application of seismic isolation and energy dissipation technologies for buildings in Japan
}

\author{
M. Higahsino ${ }^{1,2}$, N. Kani ${ }^{2}$, Y. Ohta ${ }^{1} \&$ H. Hamaguchi ${ }^{1,2}$ \\ ${ }^{I}$ Structural Engineering Section, Takenaka R\&D Institute, Japan \\ ${ }^{2}$ Japan Society of Seismic Isolation (JSSI), Japan
}

\begin{abstract}
Reflecting the extensive damage caused by the 1995 Hyogo-ken Nanbu Earthquake, the number of seismically isolated buildings in Japan has increased dramatically and the total number now exceeds 2000 . The number of buildings with response control has reached 700 . In the most recent development, many super high rise buildings with seismic isolation have been designed and constructed. Further development of seismic isolation technology has led to its application to semiconductor manufacturing facilities. As with seismic isolation, similar advances have been made in response control technologies for buildings in Japan. This report summarizes the current statistics of seismically isolated buildings and response controlled buildings. Also, this report introduces the most recent developments of seismically isolated super high rise buildings and seismically isolated semiconductor facilities. This report also introduces the development of energy dissipating plates utilizing corrugated steel walls for response control.
\end{abstract}

Keywords: seismic isolation, response control, super high rise building, semiconductor manufacturing facility, corrugated steel plate.

\section{Introduction}

Japan is situated at the complex intersection of the Eurasian, North American, Pacific and Philippine tectonic plate boundaries, a region having one of the highest risks of severe seismic activity in the world. Japan has been experiencing many large earthquakes in its history. The experiences of severe earthquakes 
around the entire country have led to the intensive development of new technologies and innovation in earthquake engineering. Recently, it resulted in widespread application of innovative seismic structural technologies in Japan.

The experience of the 1995 Hyogo-ken Nanbu Earthquake renewed not only engineers', but also the building owners' understanding that it is important to limit damage to a low and repairable level, or even to keep buildings fully functional and operational after a severe earthquake. This awareness resulted in a dramatic increase in the implementation of response control and seismic isolation technologies in buildings in Japan after 1995, along with research and development, and production for control devices.

The needs for higher safety in buildings led to further developments in seismic isolation and response control technology. The requirement of safety in residential buildings led to the development of seismic isolation of super high rise buildings. The semiconductor manufacturing facilities were also the buildings in dire need of a high level of safety to protect their production lines.

This report summarizes the state of the art of seismic isolation and response control in Japan. Also, the report introduces some of the most recent developments in seismic isolation and response control technologies.

\section{State of the art}

The development of the technologies of seismic isolation began in early 1980s in Japan. But the construction of building with seismic isolation was mostly limited in buildings owned by construction companies, thus the number of buildings were small. However, the number of seismically isolated buildings in Japan has increased dramatically since the 1995 Hyogo-ken Nanbu Earthquake and the total number exceeds 2000 by the year 2006. Additionally, the number of detached houses with seismic isolation has reached 3000. Figure 1 shows the number of buildings with seismic isolation by year (not including detached houses). Currently, half of the buildings with seismic isolation in Japan are condominium buildings. The number of detached houses using isolation increased dramatically in 2000, largely as a result of the development of low-cost sliding bearings.

Base shear coefficients used in the design of superstructures are summarized in Figure 2. About $75 \%$ of the buildings were designed for a base shear coefficient less than 0.15 .

The average value of response displacement for the seismically isolated buildings is about $0.25 \mathrm{~m}$ at input Level 2 , and the average isolation gap, the clearance between the superstructures supported on the isolation devices and surrounding retaining wall, is about $0.50 \mathrm{~m}$, as shown in Figure 3. The horizontal axis shows License numbers of buildings approved by Building Centre of Japan (smaller numbers for earlier buildings and higher numbers for more recent).

Figure 4 shows equivalent fundamental periods of the seismically isolated buildings. It can be seen that the fundamental periods are gradually getting longer for newer isolated buildings.

Figure 5 shows the shear of buildings constructed with response control systems. Since the Hyogo ken Nanbu earthquake, engineers' attention has been 
called for response control technologies also, especially for enhancing safety of high-rise and super high-rise buildings. There are six major types of devices used for response control: mass, friction, oil, viscous (hydraulic), visco-elastic, and steel. Of all these types, steel dampers are the most popular. The number of building using response control systems has increased gradually since the 1995 Hyogo ken Nanbu earthquake and the figure has exceeded 700 by the year 2006.

\section{Seismic isolation of super high rise buildings}

The convenience of living in a large city, where residencies are close to their work place, has led to the increase of super high rise condominiums in Japan. However the assets are once in the lifetime value that the requirement for the safety against earthquakes is prominent. These conflicting needs and requirements have converged to the solution in developing seismic isolation for super high rise buildings.

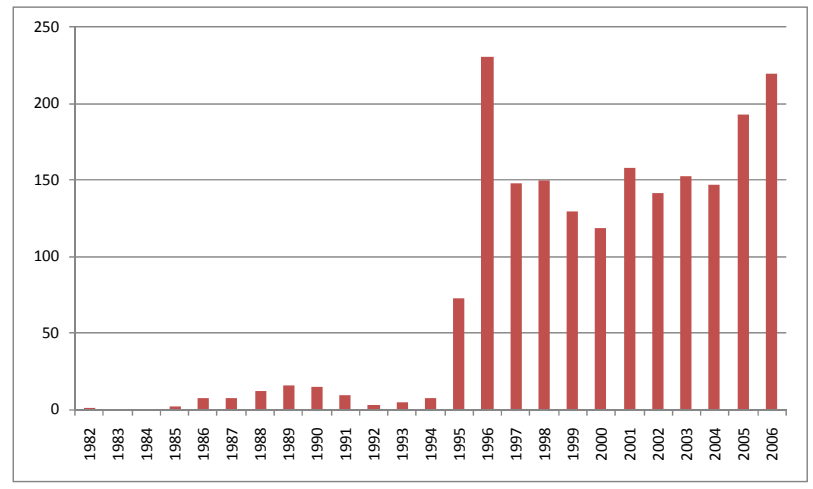

Figure 1: Number of seismically isolated buildings in Japan, by year (not including detached houses).

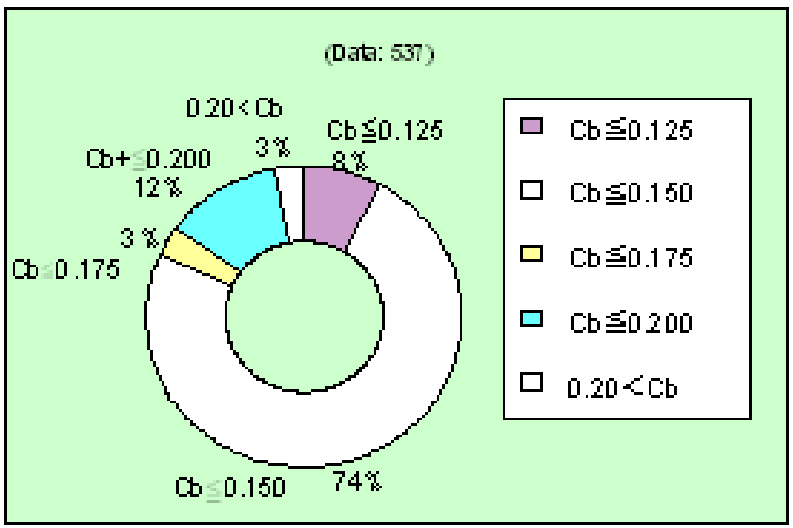

Figure 2: Base shear coefficients for design. 


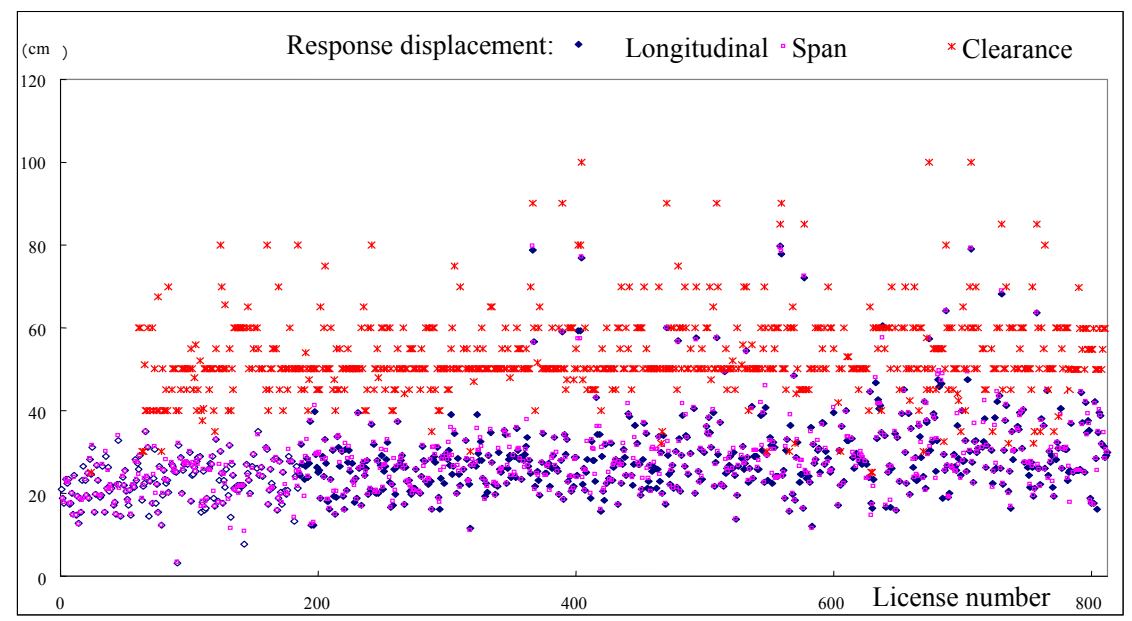

Figure 3: $\quad$ Response displacement and horizontal clearance of level 2.

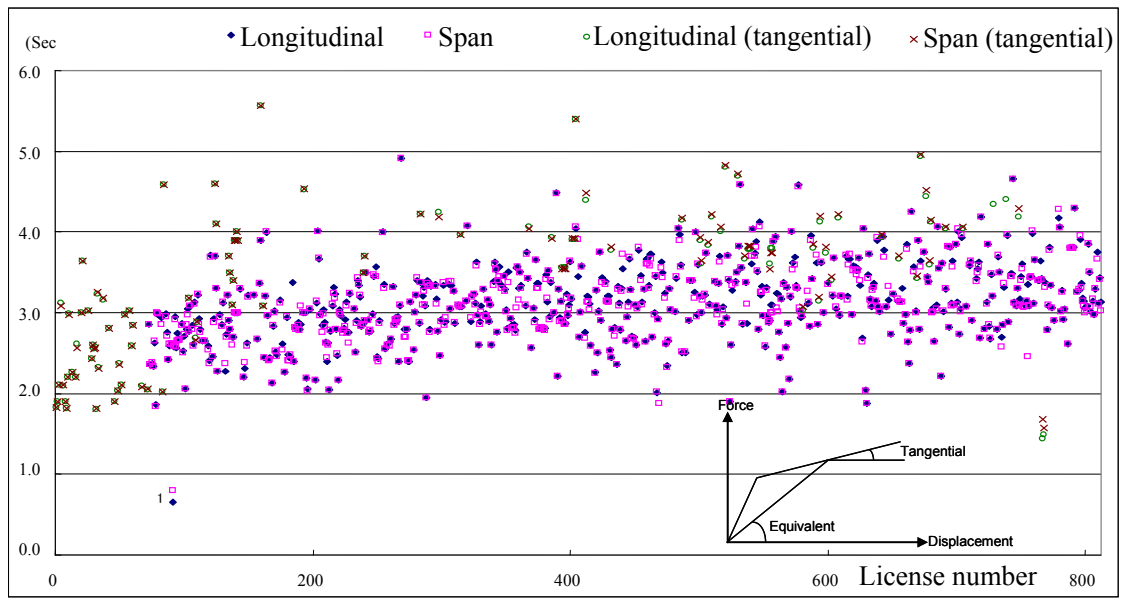

Figure 4: $\quad$ Equivalent fundamental periods of seismically isolated buildings.

The most frequently asked question about the isolation of super high rise building is the concern of the overturning of the building. In contrast to our imagination, the overturning problem is a dimensional problem. There are three conditions, acceleration, velocity and displacement. The displacement condition is that to overturn the building, the displacement of the building must be larger than half the length of building plan. If the building in consideration has $30 \mathrm{~m}$ length of the plan and $150 \mathrm{~m}$ height, the displacement of the building must be larger than $15 \mathrm{~m}$ to make the building to fall dawn. We still need to add conditions of velocity and acceleration, but we can see that the earthquake can hardly fall the buildings down. 


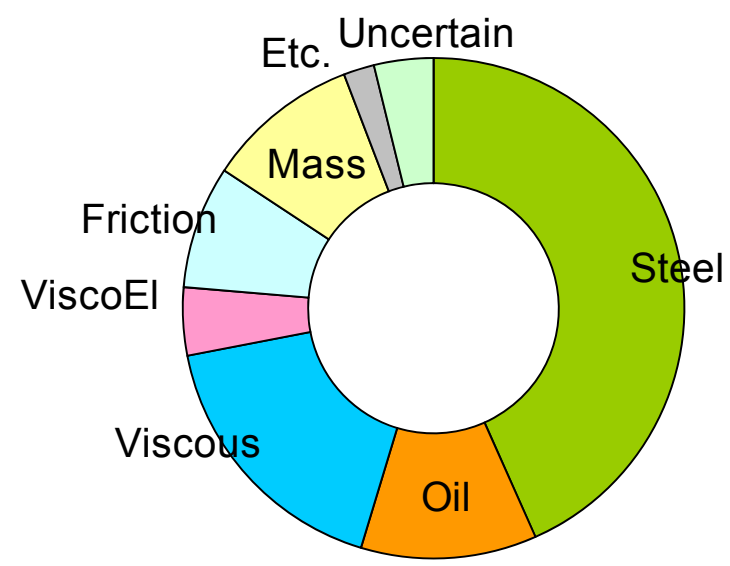

Figure 5: Shear of response controlled buildings by device types in Japan.

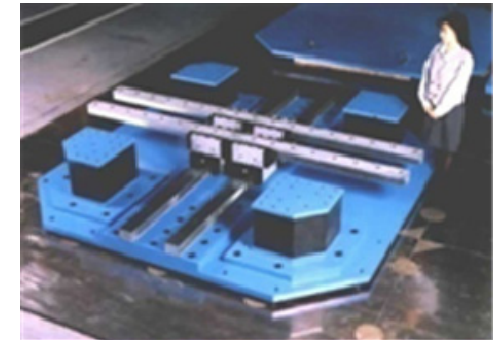

(a) Example of roller bearing

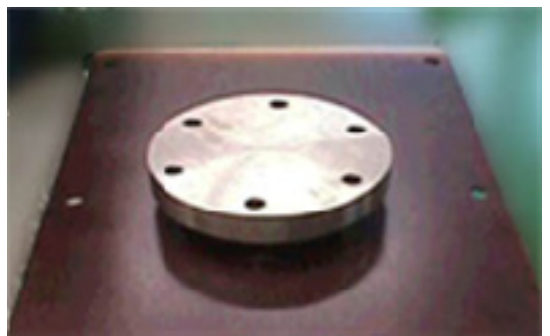

(b) Example of sliding bearing

Figure 6: $\quad$ View of base isolation devices with no restoring force.

The technology to be developed was the bearings without restoring force. The most popular devices are rubber bearings, which can support the building and also can provide restoring force. However, rubber bearings have limitation in the capacity of face pressure, and it is usually $15 \mathrm{Mpa}$ for the highest. This value is for the long term vertical load, which is the weight of the building. Also the shear elastic coefficient is $0.4 \mathrm{Mpa}$ for the smallest. These two values limit the natural period to almost 4 seconds for the longest when used with hysteresis dampers.

When considering a building of $100 \mathrm{~m}$ height, its natural period of first mode will be around 2 to 3 seconds. To make the inter-story drift in superstructure small enough to avoid the damage during earthquake, the natural period in seismic isolation interface must be at least 2 to three times longer compared to that of superstructure. This means the natural period should be longer than 4 seconds. To meet with this requirement, the bearing which has no restoring forces was developed. Figure 6 shows two major devices which have no restoring force, roller bearing and sliding bearing. When discussing mechanical 


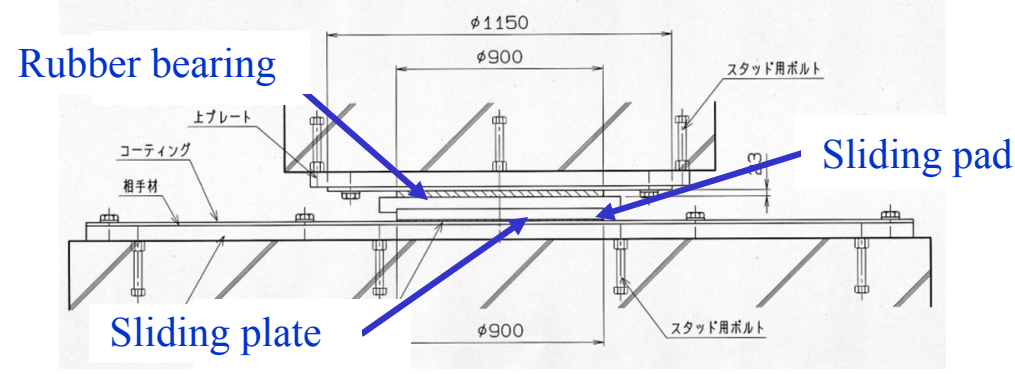

Figure 7: Configuration of typical sliding bearing.

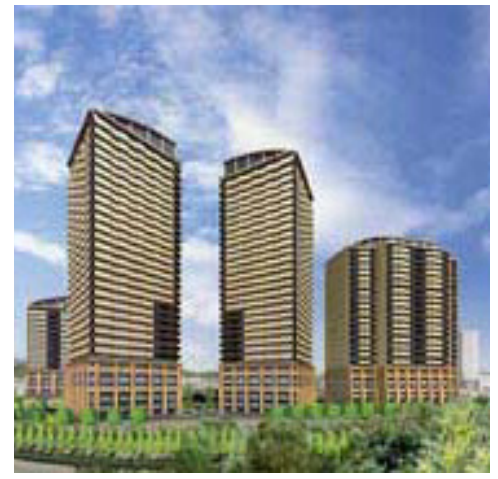

(a) Building in Kanto area

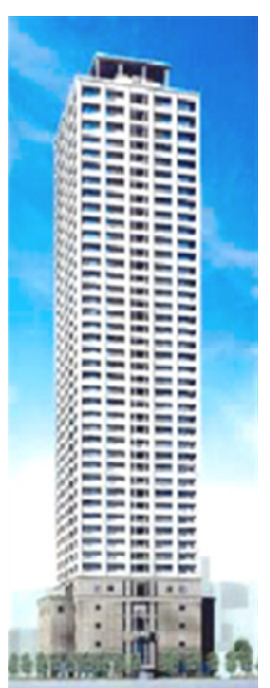

(b) Building in Kansai area

Figure 8: $\quad$ Super high rise buildings with seismic isolation.

behaviour, these two devices are almost the same only roller bearings have smaller friction coefficients of almost 0.01 , while sliding bearings have 0.02 to 0.1 . However, the price of device is much smaller for sliding bearing, thus sliding bearings are more popular in practice.

Figure 7 shows the typical cross section of a sliding bearing. The bearing consists of sliding plate, sliding pad, and thin rubber bearing. Sliding plate is usually made of stainless steel, and sliding pad is typically made of PTFE, popularly known as Teflon. The friction coefficient between these two materials will be 0.07 to 0.1 . To make the friction smaller, the coating over sliding plate is often used to make it to 0.02 to 0.03 . In considering the heat produced by the friction, smaller friction coefficient is preferred since PTFE will be softened over 300 degree $\mathrm{C}$ temperature. 
Figure 8 shows the view of two examples of the super high rise buildings which employed seismic isolation. Both of them are condominiums.

\section{Seismic isolation of semiconductor manufacturing facility}

Another building type which is extremely sensitive to earthquake excitation is semiconductor manufacturing facility. It not only must be protected from strong earthquake, but it also needs to be protected from small to mid level earthquakes. Their manufacturing lines are so sensitive that their production may be halted by small earthquake causing the loss of thousands of millions of yens. At the same time the facility has to be rigid enough not to be shaken by ceaseless micro tremor. The manufacturing devices requires severe vibration environment to ensure their production in microns to nano scale precision.

The characteristics of the buildings against micro tremors and earthquakes are depicted in Figure 9 and Figure 10 namely. In Figure 9, conventional seismically engineered building clears the displacement and acceleration criteria for all considering frequency range. However, regular seismic isolation structure, which employs hysteresis damping, cannot clear the requirement of displacement in low frequency range where its natural period exists. These peaks must be suppressed. In Figure 10, it can be seen that regular seismic isolated building cannot show their good performance for small and mid level earthquakes.

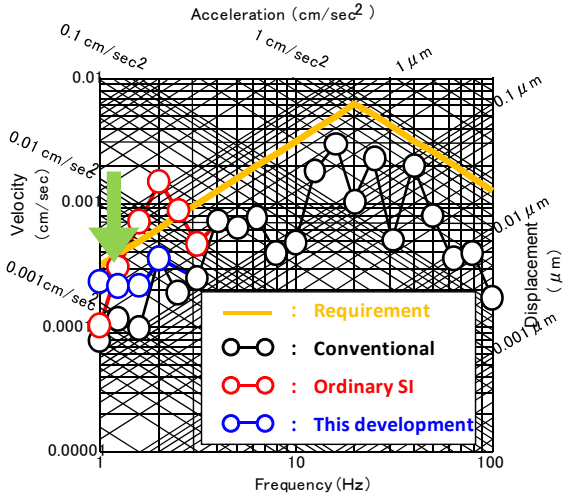

Figure 9: Characteristics for micro tremor.

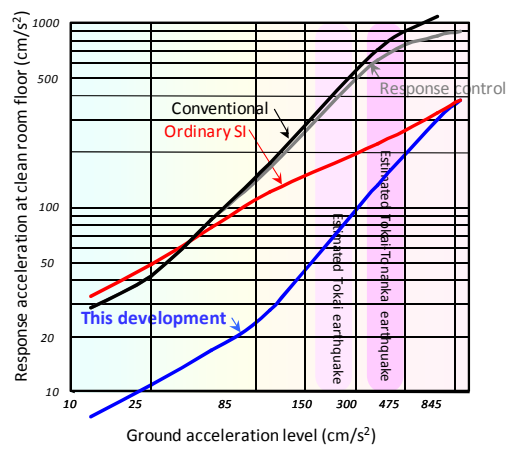

Figure 10: Characteristics for earthquake.

The solution Takenaka has achieved is to use viscous dampers together with natural rubber bearings. Viscous damper absorbs vibration energy from small to large displacement induced by small to large earthquakes. Poly-Butane polymer compound is very viscous material but it shows the viscosity under small displacement when it is placed between two steel plates. The construction of viscous damper is shown in Figure 11. 

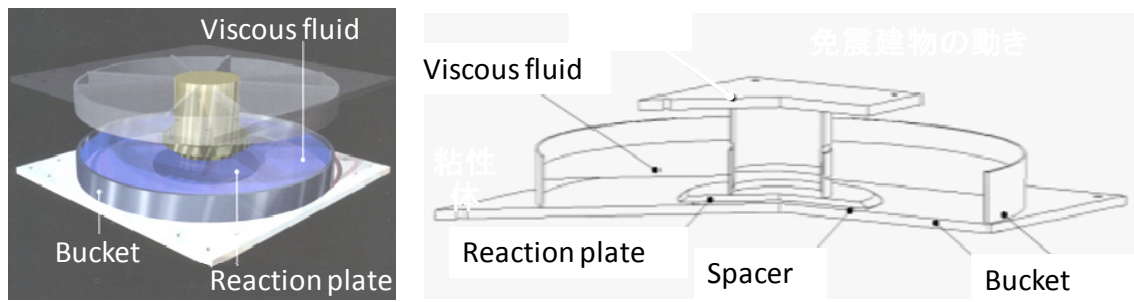

Figure 11: Construction of viscous damper.

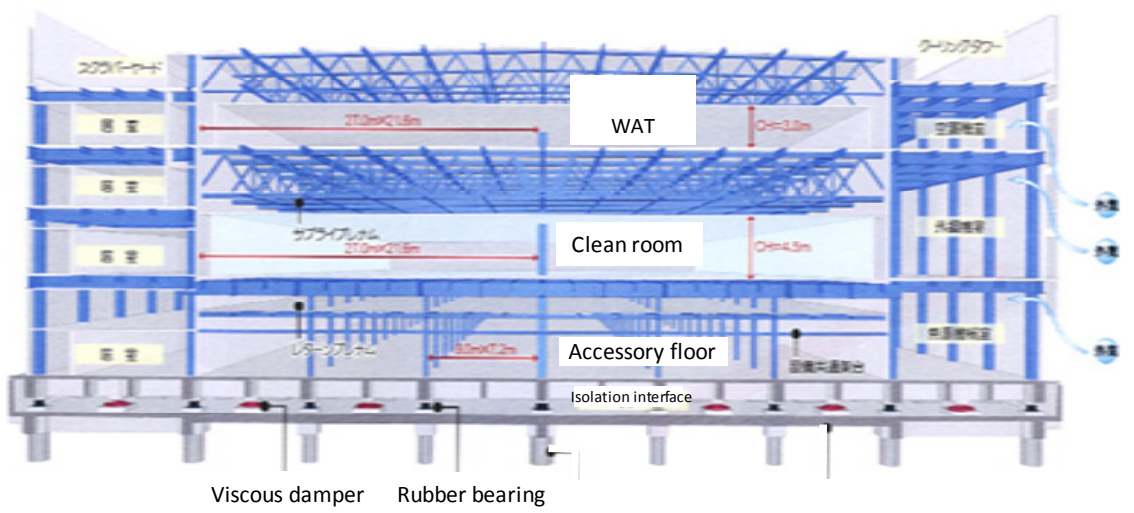

Figure 12: Cross section of semiconductor manufacturing facility with SI.

The cross section image of semiconductor manufacturing facility using viscous dampers and rubber bearings is shown in Figure 12. This system is named "Takeneka Viscous Seismic Isolation System". The system has already been employed in three semiconductor manufacturing facilities in Japan.

\section{Corrugated steel panel for response control}

Although seismic isolation is the most preferred solution to provide high safety profile against strong earthquake, not every building is feasible to equip with isolation system depending on building location, restriction of site, the characteristics of superstructure etc. To achieve higher safety level, response control is the reasonable measure. As is described in previous section, there are various types of devices for response control. Among all, buckling restrained braces is the most popular device to add extra damping to the building, because of its simplicity and mostly for its cost. However, these dampers are mainly used for steel structures. For reinforced concrete structure, conventional walls are still the major seismic member.

Wall system of RC structure provides high strength, but it also has high stiffness and the high stiffness is not always preferred when the rotation of the 
Flexible in vertical deformation

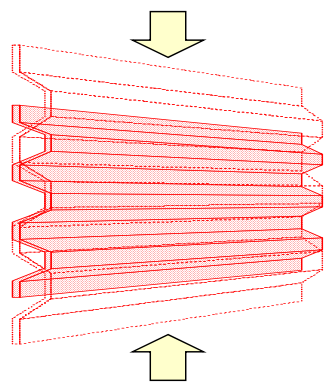

\section{Resistant in shear deformation}

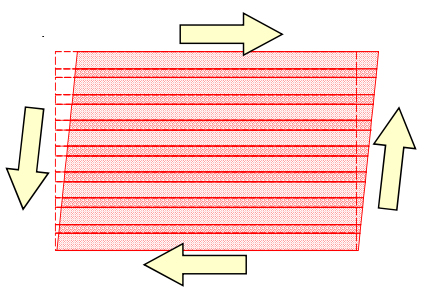

Figure 13: Characteristics of corrugated steel panel.

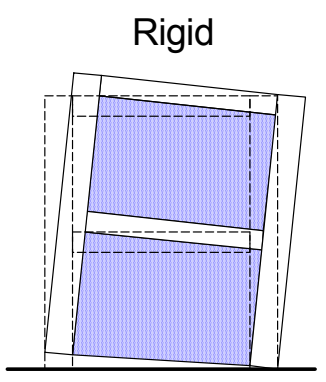

$\underline{\mathrm{RC}}$ wall
Allows deformation in moment frame

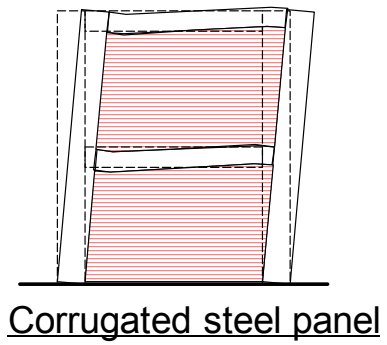

Figure 14: Difference of the behaviour between RC wall and corrugate steel panel.

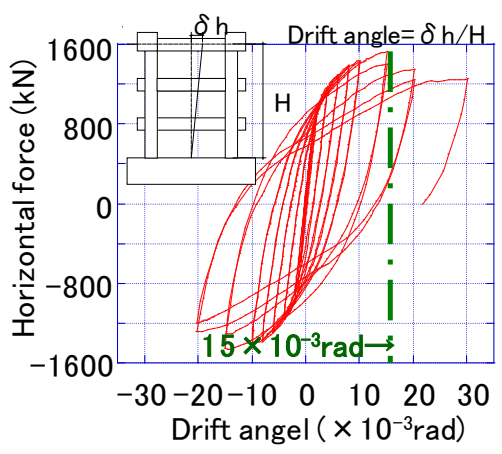

Figure 15: Hysteresis of moment frame with corrugate steel panel.

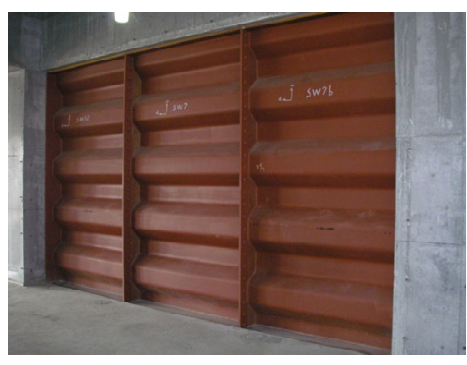

Figure 16: Installed view. 
wall becomes the issue. Takenaka Corporation put the eyes on corrugated steel panel which provides the same strength and stiffness to shear deformation while it has flexibility in vertical deformation (Figure 13). The image of difference between RC wall system and corrugated steel panel is depicted in Figure 14. The energy absorbing characteristics of the system has been tested with the specimen shown in Figure 15 along with the test result. The high energy absorbing capacity has been confirmed with the test. Figure 16 shows the photos of corrugated steel panel installed in a building frame.

\section{Conclusions}

Seismic isolation and response control have become popular dramatically since Hyogoken Nanbu earthquake. The number of buildings with these technologies is increasing. The popularity of technologies lead to further development of seismic isolation to super high rise building and semiconductor manufacturing facilities. For response control, the requirement of effective damping absorption lead to the development of corrugated steel panel. The developments of many new technologies are still on the way. However, the number of buildings requiring extra safety is still large. In addition, the recent earthquake observation made clear that the capacity required to seismic system will be much higher than current understandings. The engineers and researchers are still required rigorous effort to enhance safety of all kinds of buildings to achieve sufficient safety level through new technologies.

\section{References}

[1] Higashino, M. and Okamoto, S., Response control and seismic isolation of buildings, Taylor \& Francis, 2006.

[2] Ohta, Y., et al, Study on mechanical behavior of wall with corrugated steel plate, 22563 C-1, AIJ annual meeting, 2006. 